\title{
Redes globais, laços locais: memórias da cidade de Lontras no Orkut
}

\author{
JeAn Segata \\ Doutorando em Antropologia Social pela UFSC \\ Professor da UDAVI \\ jeansegata@gmail.com
}

\begin{abstract}
Resumo Como parte das reflexões originadas de minha pesquisa de mestrado em antropologia, onde fiz uma etnografia em um ambiente construído no enredamento de algumas comunidades do orkut, o MSN e a cidade de Lontras, no interior do Estado de Santa Catarina, neste artigo busco refletir especialmente sobre uma das diversas formas e qualidades de interação nas redes sociotécnicas: a possibilidade de construção coletiva de memória. O nó central desta discussão se dá em uma comunidade do orkut que "homenageia o colégio" da cidade de Lontras, possibilitando o [re]encontro de alunos de diversas gerações, que construíram um ambiente de interação onde se pode perceber o caráter relativo da localidade e da globalidade dessas redes.
\end{abstract}

Palavras-chave: antropologia do ciberespaço; redes sócio-técnicas; memória coletiva; localidade; globalidade.

Quem você conhece?

Participe do orkut para ampliar o diâmetro do seu círculo social.

"Página Inicial do Orkut" - www.orkut.com

E

Ra meados de agosto De 2004, o orkut já estava "no ar" há oito meses. De início eu não lhe atribuí muita importância, mas conforme os meses passavam, criei certa curiosidade, alimentada especialmente por duas situações: a primeira delas, pelo fato de que eu já vinha fazendo leituras sobre o ciberespaço onde percebi que um número bastante significativo de manchetes em revistas de grande circulação nacional vinha tratando do que elas chamavam na época de "o fenômeno orkut"1; da mesma forma, encontrei sites de vendas e leilões, onde se oferecia convites para o orkut por preços absurdos.

A segunda situação, ligada à primeira, era potencializada pelo fato de que cada vez que eu tentara participar do orkut, minha entrada não era permitida por eu não possuir um convite de algum

1 "Orkut: como entender este fenômeno". Revista Superinteressante, setembro de 2004; "Você também está no Orkut". Revista Época, n. 326, 16/08/2004; "A vida na era do Orkut". Revista Galileu, n. 158, 09/2004. 
participante do dito site. Restara-me refletir sobre a pergunta destacada na sua página inicial: Who you know? ? $^{2}$. A pergunta me incomodava muito, mas não exatamente em relação às pessoas que eu conhecia - próximos ou distantes, eu conhecia um número significativo de pessoas. Antes sim, o que me incomodava era pôr-me em questão sobre por quem eu era conhecido. Afinal, se passara cerca de oito meses, e até então eu não havia ganhado um convite para entrar no dito "fenômeno".

Inquieto, eu me perguntava como seria possível receber um convite para fazer parte de "uma rede de amigos confiáveis", incubada nos laboratórios do Google, na Costa Oeste dos Estados Unidos, se eu morava no interior do Estado de Santa Catarina, aparentemente tão distante daqueles que poderiam me conhecer e confiar a mim um convite para participar dessa "rede de amigos confiáveis". Foi então nesse mês de agosto de 2004, que recebi via e-mail, de uma ex-colega de graduação, o esperado convite para "fazer parte orkut".

A curiosidade nativa da época foi aos poucos se transformando em problema acadêmico e o orkut serviu como campo para minha pesquisa de mestrado em Antropologia Social ${ }^{3}$. Compreendido como um lugar praticado (De Certeau, 2003) - que me fez repensar as múltiplas possibilidades de construções de redes e nós, que possibilitam múltiplas formas e qualidades de interação, no ciberespaço - o orkut é um espaço que me fez relativizar as dimensões de globalidade e localidade das redes sociotécnicas no ciberespaço. Tomando como campo as relações entre o orkut e a cidade de Lontras, é justamente sobre essas dimensões de globalidade e localidade e sobre uma das múltiplas formas e qualidades de interação, nesse caso a construção coletiva de memórias, que limito esta reflexão.

\section{Lontras nas redes do orkut, ou o orkut nas redes de Lontras}

\author{
...mesmo uma rede ampla continua \\ a ser local em todos os pontos.
}

Bruno Latour - "Jamais Fomos Modernos".

O orkut, no ciberespaço, se auto-define como uma "comunidade on-line que conecta pessoas por meio de uma rede de amigos confiáveis"4. Nele é possível a criação de uma espécie de "página pessoal", constituída por perfis (social, pessoal e profissional), onde cada participante preenche uma série de questionários sobre as suas características e preferências (acadêmicas, profissionais, artísticas, esportivas, religiosas, culinárias, afetivas) e a resposta de uma pergunta mais ampla, quem eu sou, entre outras. É possível também, a composição de um espaço dedicado a postagens de fotos - meu álbum e recentemente, um espaço para postagem de vídeos - meus vídeos ${ }^{5}$; e outro espaço dedicado a receber recados de outros participantes do orkut - meus recados; que geralmente compõe uma lista de contatos - meus amigos; que podem ser adicionados mutuamente uns às "páginas pessoais" dos outros. Nessas "páginas pessoais", chamadas pelos nativos de meu orkut, há ainda um espaço chamado minhas comunidades composto pela adição/filiação às comunidades no orkut que são construídas pelos próprios participantes. Cada um desses espaços funciona com uma espécie de "link sem fim", que leva o participante de uma comunidade para outra, de uma "página pessoal" para outra, numa lógica - não lógica - de associação que forma redes.

De maneira geral, as redes são como um conjunto de nós interconectados: são pontos que ligam pontos, se entrecruzam, formam fluxos e nós. Elas são uma prática bastante comum em diversos tempos e sociedades, especialmente nos domínios das economias, dos mercados, da comunicação, tendo sua emergência pelo crescimento das cidades, substituindo lugares e flexibilizando as relações nestes contextos "mais complexos". Com a emergência do ciberespaço a idéia de rede passa a ser discutida tanto como "a grande rede" que tudo liga e, ao mesmo tempo, como o fim da comunidade compreendida como loci de compartilhamento de valores, em detrimento às redes - "frágeis", impessoais, "inter-impessoais" e individualizantes (Castells, 2003). No entanto, nessa reflexão, a noção de rede que para mim mais se aproxima do orkut, se remete às interações de geometrias variáveis que são processualmente construídas em função dos interesses dos sujeitos que formam essas redes, pensadas, muito mais em termos de localidade, do que de globalidade.

Segundo Latour (2005), local e global são conceitos bem adaptados às superfícies e à geometria, mas inadequados para se pensar as redes, especialmente as redes sociotécnicas no ciberespaço, que transcendem a geografia e a geometria. Latour (2005) ao se referir ao

2 "Quem você conhece"; até meados de 2005, o orkut era disponibilizado apenas em Língua Inglesa, quando então passou a ser disponibilizado em mais de uma dezena de idiomas, inclusive em Língua Portuguesa.

3 Minha pesquisa de mestrado resultou na dissertação intitulada "Lontras e a Construção de Laços no Orkut" - PPGAS/UFSC, 2007. Agradeço ao CNPq pela concessão de bolsa de estudos que possibilitou a realização da pesquisa. Agradeço também à Universidade para o Desenvolvimento do Alto Vale do Itajaí - UNIDAVI, onde atualmente sou professor de antropologia, pelo apoio à publicação deste trabalho.

4 www.orkut.com.

5 Este "serviço" começou a ser disponibilizado em março deste ano, de forma que ele não é descrito e analisado neste trabalho. 
modelo da ferrovia, dá boas pistas para pensarmos na localidade das redes. Nas suas palavras:

[...] no caso das redes técnicas, não temos a menor dificuldade em reconciliar seu aspecto local e sua dimensão global. São compostas de locais particulares, alinhados através de uma série de conexões que atravessam outros lugares e que precisam de novas conexões para continuarem se estendendo (Latour, 2005, p. 115).

Nesse sentido, essas redes não são superfícies, mais sim linhas conectadas, que mesmo amplas (globais), continuam sendo locais em todos os seus pontos. Essa relativização do global e do local parece se tornar mais clara se tomarmos cada participante do orkut como um desses pontos que ajuda a tornar a rede local e, ao mesmo tempo, global. Dessa forma, para que a rede tenha continuidade é preciso que um ponto se ligue a outro ponto, fazendo a rede formar novas conexões que atravessam outros lugares; assim cada participante se ligaria a outros tantos participantes, mais ou menos próximos, ampliando cada vez mais a rede, sem perder a localidade dela em seus pontos, os mais diversos possíveis e, ao mesmo tempo, ampliando-a a dimensões globais, quando vista como um amplo conjunto de pontos locais. Nesta dinâmica, a noção proxemia parece bastante útil para se refletir sobre a constituição de redes no orkut.

Proxemia é uma noção cunhada na Escola de Palo Alto, na Califórnia, que na década de 1960 reunia um grupo interdisciplinar de estudiosos, especialmente da psicologia e da sociologia - como Gregory Bateson, Erving Goffman e Edward Hall (1963; 1989) - preocupados em estudar o que chamavam de "nova comunicação". Esta considerava os diversos sistemas interpessoais, especialmente as distâncias construídas entre as pessoas, como parte daquilo que se compreendia por cultura. Nesse sentido, por exemplo, as pessoas não falariam apenas línguas diferentes, mas elas habitariam mundos sensórios diferentes - espaços, mais ou menos amplos, dependendo do contexto. Entretanto, percebo como particularmente mais inte- ressante para descrever esses processos de constituição de redes com a união de pontos de proximidade, mais ou menos locais no ciberespaço, a noção de proxemia utilizada por Maffesoli (2006), para quem a proxemia "remete, essencialmente, ao surgimento de uma sucessão de "nós" que constituem a própria substância de toda a socialidade" (Maffesoli, 2006, p. 193-194). No orkut, esses nós seriam construídos no intrincado "jogo" do alguém, que conhece alguém, que conhece alguém, que conhece alguém (...), onde cada um seria um elo dessas "correntes" formadoras de espaços, que ligam direta, ou indiretamente todos os participantes do orkut, formando uma ampla rede, mas que em alguns pontos, como em algumas das chamadas comunidades ${ }^{6}$ aglutinam uma série de pontos locais (participantes que possuem algum tipo de ligação mais próxima), formando redes mais locais, especialmente complexificadas pela dimensão off-line. Minha experiência de alguém que está na internet há alguns anos e que percebia outrora uma acentuada busca por "novas amizades", "novos contatos" - uma busca por pessoas de lugares diferentes, distantes, possibilitado pela desterritorialização que o ciberespaço oferece (não que o orkut não oferecesse esse tipo de buscas e de ligações) e que agora via o crescimento de espaços onde o voltar, o "reterritorializar", o reencontrar e religar àqueles que antes - espaços e pessoas - estavam próximos e que agora se faziam distantes, era emergente. No orkut, eu entrava em uma rede bastante ampla e, ao mesmo tempo, constituída por uma multiplicidade de nós, alguns deles bastante locais como o constituído na, com e pela a cidade de Lontras.

Com pouco mais de nove mil habitantes, Lontras está localizada na região do Alto-Vale do Itajaí, distante cerca de 200 quilômetros da capital do Estado de Santa Catarina, Florianópolis. Sua economia depende, em grande parte, das pequenas propriedades agrícolas, de algumas pequenas indústrias e nos últimos anos, mais substancialmente, de pequenas malharias e confecções alocadas em espaços residenciais, além do pequeno comércio local. Costuma-se dizer da cidade, que ela é apenas um dormitório da cidade vizinha -

6 O termo comunidade aparece em itálico, pois está sendo utilizado como nomenclatura que a plataforma do orkut sugere e/ou como adoção nativa, não configurando discussão stricto senso. Como sugere Rifiotis (2003) ao se referir ao conceito de "comunidade virtual", na antropologia "o que nos interessa em termos de economia analítica é mais a experiência concreta dos sujeitos que são atores neste campo do que a etiqueta pressuposta que Ihes circunscreveria o seu conteúdo" (Rifiotis, 2003, p. 12). Quando muito, numa tentativa de aproximação conceitual, comunidade, neste reflexão, à luz do que escreve Bauman (2003), se refere muito mais a uma sensação do que a uma significação: lugares "confortáveis" e "aconchegantes" constituidores de laços que ligavam os participantes, em nós de diversas qualidades, nas redes do orkut. Nesse caso, mais especificamente, aqueles que os ligavam à cidade de Lontras. Assim, mesmo considerando o fato de o orkut se auto-definir como uma "comunidade on-line", meu objetivo é tão somente o de descrever a pequena história, construída cotidianamente, de pessoas no ciberespaço e do ciberespaço na vida das pessoas. Mesmo assim, volto a reforçar os apontamentos que a antropologia têm feito (Rifiotis, 2003 ; Guimarães Jr., 2004), a respeito de noções como as de "comunidade virtual", de que estas devam ser problematizadas e postas em discussões mais aprofundadas, especialmente a noção de comunidade, amplamente discutida na tradição antropológica, tanto na etnologia como no estudo das sociedades complexas - onde podemos inserir também este projeto de construção de uma Antropologia do Ciberespaço - já que em ambos os campos, tratam-se de investigações de grupos que mantém sua unidade através de laços partilhados em espacialidades construídas em redes de interação e em espaços simbólicos, neste caso, construído na dinâmica enredadora do alguém que conhece alguém. 
Rio do Sul - em razão do grande número de pessoas que se deslocam para lá diariamente, seja para trabalhar, estudar ou fazer compras. Como cidade pequena, do interior, a maioria dos habitantes se conhece. Há, de alguma forma, ligações mais ou menos diretas e estreitas entre umas e outras pessoas: são antigos colegas de escola ou trabalho, vizinhos da rua, do bairro, participantes de alguma igreja, filhos de amigos, filhos de antigos colegas de escola, parentes próximos, ou distantes. Enfim, uma multiplicidade de laços mais ou menos viscosos e duradouros.

Especialmente para mim, Lontras é mais que uma palavra que significa um lugar geográfico, é antes, uma palavra que faz com que eu sinta um pouco de quem eu sou: é a cidade onde cresci e vivi por mais de vinte anos e onde ainda mora grande parte de minha família; também foi onde realizei meus estudos básicos, na mesma escola que viria a ser mais tarde o lugar de meu primeiro emprego formal - a Escola de Educação Básica Regente Feijó, conhecida apenas por "colégio" - e, fundamentalmente, é a cidade onde residem ainda alguns amigos. Distanciado de Lontras há algum tempo, eu a revivia em minhas memórias, como algo ideal e utópico. Parece-me que as palavras de Bauman (2003) ao se referir às comunidades, ilustram bem esse sentimento. Segundo o autor, comunidade é o tipo de mundo, que lamentavelmente não está ao nosso alcance, mas que gostaríamos de viver e que esperamos e acreditamos vir a possuir, como se estivesse sempre no futuro. Para ele, "comunidade é nos dias de hoje outro nome do paraíso perdido - mas a que esperamos ansiosamente retornar, e assim buscamos febrilmente os caminhos que podem levar-nos até lá" (Bauman, 2003, p.09). Ainda segundo o autor, comunidade é uma palavra que guarda muito mais que significados, ela guarda sensações: o que quer que comunidade signifique, é "sempre bom estar em uma comunidade" (Bauman, 2003, p.07); é nelas que buscamos a segurança e a liberdade, o que gera uma sempre tensão entre "comunidade" e "individualidade": a comunidade com a sua segurança e a liberdade da individualidade.
Talvez fosse essa a tensão que eu revivia em minhas memórias: supostas liberdades e seguranças que eu experimentava no aconchego, na familiaridade e no pacatismo de Lontras, em detrimento às experiências de aparente fragilidade, desconfiança e solidão que eu sentia residindo agora em Florianópolis, para cursar o mestrado. A cidade de Lontras, sentida então como "paraíso distante", tornava-se objeto de minhas buscas, ao menos para suspender em uma espécie de cabide, temporariamente, as fragilidades, desconfianças e solidão que pesavam sobre meus ombros, em Florianópolis ${ }^{7}$. Foi então que minhas experiências nativas de "internauta" possibilitaram que Lontras fosse, de alguma forma, reencontrada por mim no orkut, de tal modo que em pouco tempo eu me encontrava entre redes e nós que intrincavam as dimensões on-line e off-line daquela cidade, construindo um único espaço complexificado por estas duas dimensões - o ambiente Lontras ${ }^{8}$, constituído pelas comunidades "Lontras", "LONTRAS", "Estudei Regente Feijó" e "E.E.B. Regente Feijó" e a própria cidade de Lontras, que inspirou a criação dessas comunidades no orkut. Dessa forma, o ambiente trazia elementos bastante significativos da cidade de Lontras - ou mesmo, pelo fato de que as relações que eram construídas on-line, eram continuidades, frutos, rupturas ou tensões de relações vividas na dimensão off-line da cidade -que em uma rede bastante ampla como o orkut era um ponto bastante local, com múltiplas potencialidades de promover interações ${ }^{9}$, ligações e religações.

Na primeira vez que digitei "Lontras", na ferramenta de buscas de comunidades no orkut, lembro-me, apareceu uma grande quantidade de comunidades nomeadas "lontras são animais lindos"; "preserve as lontras"; ou apenas "lontras" - dedicada, como dizia sua descrição, às pessoas que gostam de brincar muito tempo na água. Enfim, os espaços "Lontras" no orkut que eu encontrei na ocasião, estavam ligadas ao animal lontra (Lutra longicaudis), mamífero que era encontrado em grande quantidade nos rios da cidade de Lontras, dando origem ao nome da cidade, mas que não eram dedicadas à cidade de Lontras. Como eu não havia encon-

7 Bauman (2003) sugere o exemplo dos "vigilantes do peso", como uma espécie de "comunidade estética" - cabide - onde se vive por instantes a "sensação boa" de liberdade e segurança, para depois "voltar para a vida cotidiana".

8 Em relação à noção de ambiente, me refiro a sugestão de Guimarães Jr. (2000, 2004), para quem haveria uma distinção entre "plataformas" e "ambientes" de interação (compreendidas as diversas formas e qualidades de interação). Segundo ele, "as plataformas são as diferentes tecnologias (tais como softwares e conexões de internet) que permitem a comunicação entre dois ou mais usuários e ambientes de sociabilidade, por sua vez, são os espaços sociais estabelecidos através de uma ou mais plataformas" (Guimarães Jr., 2004, p. 125 - nota de rodapé). Esse tipo de distinção entre plataforma e ambiente é útil, segundo o autor, para que se possa demarcar os contornos simbólicos dos grupos sociais on-line que se utilizam, muitas vezes, de mais de uma plataforma a fim de construir um ambiente. Neste sentido, a plataforma do orkut é um serviço (servidor/ software) filiado ao Google (um servidor/software maior). À medida que as pessoas constroem redes, ambientes e interações nesta plataforma, ela é de alguma maneira, humanizada, ganhando formas, qualidades e sentidos. Cf. a distinção entre plataformas e ambientes sugerida por Guimarães Jr., 2000, 2004.

9 Neste sentido, compreendo que estas interações, em muitos momentos podem assumir formas e qualidades variadas, contextuais, ou híbridas (Hannerz, 1997) de sociação, tais quais, sociabilidade, conflito, secretismo, ludismo (Simmel, 1983a, 1983b, 1999, 2006) e/ou socialidade e proxemia (Maffesoli, 2001, 2006), como aparecem problematizadas ao longo do trabalho. 


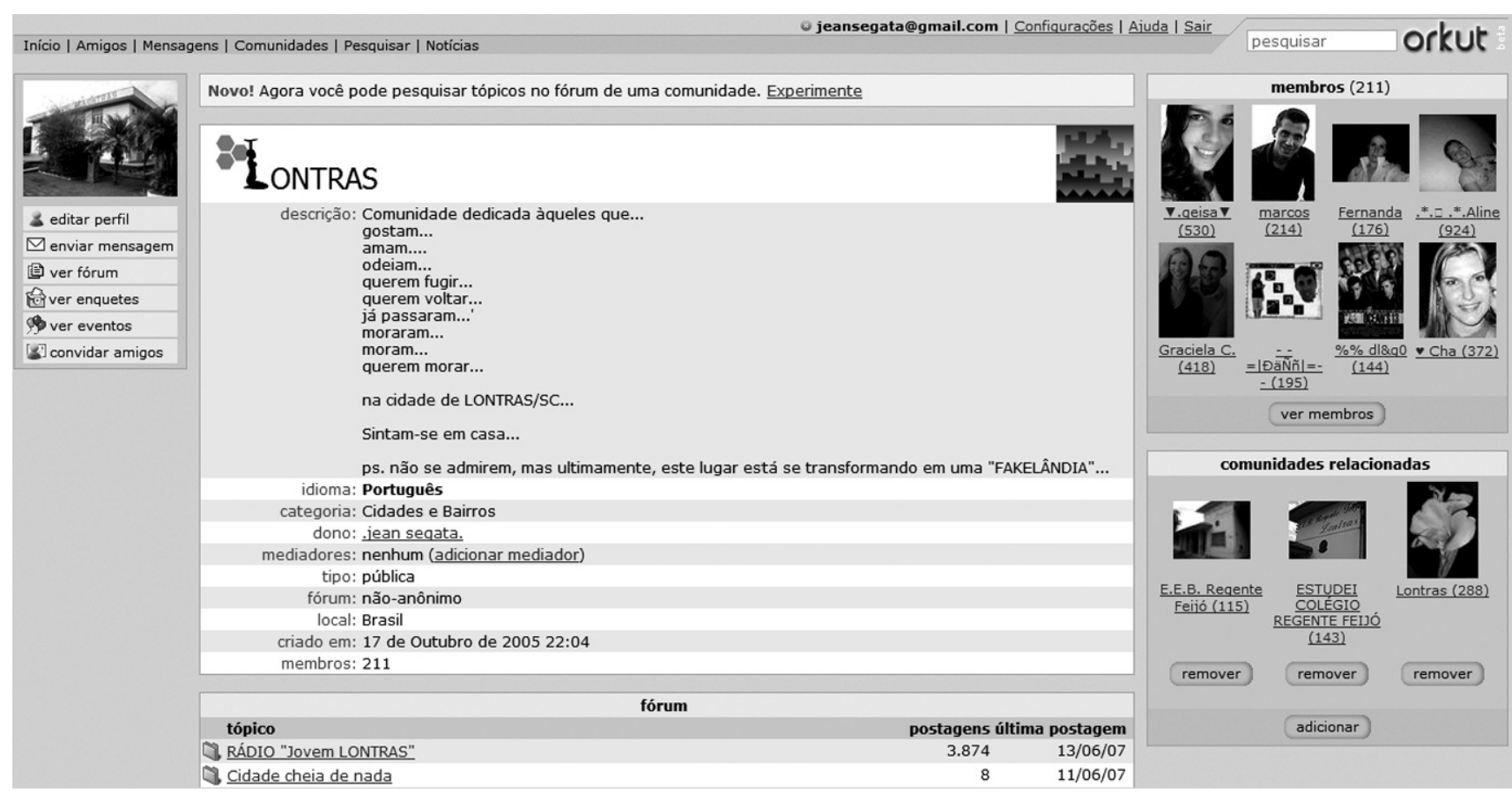

Figura 1: Página Inicial da Comunidade Lontras. http://www.orkut.com/Community.aspx? cmm=5836383

trado nenhuma comunidade sobre a cidade de Lontras, resolvi eu mesmo criar a "comunidade LONTRAS", que atualmente conta com cerca de 210 membros.

Como aparece na figura abaixo, que mostra parte da página inicial dessa comunidade, pode se perceber que eu a descrevi de maneira bastante simples e ao mesmo tempo abrangedora. No caso, se pode ler que este seria um espaço para "aqueles que amam, gostam, odeiam; querem fugir, voltar, morar; para os que moram, ou moraram", enfim, aqueles que de alguma maneira estão ligados à cidade de Lontras. No alto, à esquerda, aparece sua foto de exibição que consiste na fachada da Prefeitura Municipal de Lontras, o que, em certa medida teve a sua intencionalidade: Lontras, como pequena cidade do interior, tem belezas naturais exuberantes, entretanto, o que mais caracteriza a cidade são o prédio da Prefeitura, que marca o "ponto zero" da cidade e o prédio da igreja da Paróquia Santa Luzia, de arquitetura modernista, formando um octógono, também próximo à Prefeitura e, em frente à escola de Educação Básica Regente Feijó - o Colégio.

Essa fachada da Prefeitura é, sem dúvida, um dos elementos que mais caracteriza a pequena cidade. Ela aparece nas fotos de propagandas e materiais oficiais do município e, mais que isso, ela aparece nas falas de algumas das pessoas com as quais eu conversava sobre Lontras, como aquela imagem que, ao chegar à cidade depois de alguma viagem, ou para alguma visita, se apresenta como anfitriã do município, ou mesmo, quando se está longe, é uma das imagens que compõe as lembranças daquele pequeno lugar.

Nesse sentido, ao levar para a comunidade no orkut a imagem da fachada da Prefeitura, tive a intenção de fazer emergir aquela sensação de chegada, de retorno ou lembrança de Lontras (ao menos hoje, tenho essa impressão de assim o ter feito). Além do mais, a fachada da Prefeitura compõe a paisagem de um dos pontos-de-encontro das pessoas em Lontras - é a praça da Prefeitura, com seus bancos, seu velho chafariz desativado e do "Bar do Scheidt", pequeno restaurante que reúne um razoável número de pessoas - todos às sombras daquele prédio. Ali, se representa aquilo que se poderia chamar, tal a sugestão de Bauman (2003), de comunidade em Lontras e a comunidade assim criada no orkut parecia estender a cidade de Lontras até o orkut. De fato, durante minha pesquisa no ambiente Lontras em uma conversa no tópico intitulado "Rádio Jovem Lontras" nesta comunidade, fiz uma espécie de enquete sobre a foto de apresentação e, tive como respostas que aquela era a melhor apresentação para o espaço já que, como apontava um dos seus participantes, "tudo acontece ali naquela pracinha".

De maneira geral, essa é uma das maneiras de construir uma espécie de cidade em dois mundos, de tal maneira que as fronteiras entre esses mundos off-line e on-line - pudesse aos poucos tornar-se cada vez mais porosa, à proporção que com a entrada de cada vez mais participantes naquele espaço, se pudesse sentir uma espécie de ambiência constituída por laços subjetivos, transformando aquele espaço no orkut como parte do espaço off-line e ao mesmo tempo transformando o espaço off-line da cidade de Lontras em um pedaço do orkut. Para além do on-line e offline, eram dois mundos em um só, se confundindo, se constituindo como um ambiente que pudesse servir de vínculo para a manutenção das amizades distanciadas, das antigas relações distanciadas geograficamente 
e temporalmente - enfim: um espaço de retorno, de reencontro e religação $0^{10}$.

Entretanto, foi somente mais tarde, depois da entrada de alguns participantes nesta comunidade que eu vim descobrir que Lontras no orkut era uma rede que já estava sendo tecida: já havia uma outra comunidade "Lontras" (escrita, diferentemente daquela que eu havia feito, em letras minúsculas), também destinada a homenagear a cidade de Lontras, criada meses antes e que já contava com algumas dezenas a mais de participantes. Foi por meio dela que eu descobri as outras comunidades que viriam a constituir o ambiente Lontras: "E.E.B. Regente Feijó" (106 membros) e "Estudei Colégio Regente Feijó" (119 membros), ambas em referência ao Colégio - por onde passou a grande maioria da população da cidade. Foi assim, que eu também fui percebendo que vários participantes dessas comunidades estavam em mais de uma delas, ou até mesmo de todas elas, até porque, com o tempo, estas comunidades foram sendo afiliadas umas às outras, criando uma espécie de link direto entre $\mathrm{si}^{11}$.

De todo modo, um aspecto bastante interessante dessa união local na grande rede do orkut foi a possibilidade de construção coletiva de memórias da cidade de Lontras, especialmente nas comunidades que se referiam a Escola de Educação Básica Regente Feijó - o Colégio.

\section{O colégio: um pouco da memória de Lontras no orkut}

Por tamanha centralidade na vida dos "lontrenses", o Colégio parece ser um espaço que efetivamente constitui e participa de suas histórias de tal forma que, foi especialmente nas comunidades "E.E.B. Regente Feijó" e "Estudei Regente Feijó" que pude, de maneira mais objetiva (e antropológica), perceber que a ligação e a religação ao local, à terra, às antigas relações, não era um fenômeno subjetivo que me assaltava como nativo, como criador de uma comunidade: eu encontrara nesses dois espaços, diversos tópicos e postagens que buscavam, pela escrita coletiva de experiências vividas no Colégio, uma espécie de retorno, de reaproximação àqueles momentos especiais, significativos na vida daqueles que estavam interagindo nas rememorações de suas ligações de outrora.

Desde sua fundação em 1946 até então, do Colégio, permanece apenas o seu nome "Regente Feijó" - homenagem feita a um dos regentes que comandaram o Brasil entre o reinado de D. Pedro I e D. Pedro II - o Regente Feijó. Ao longo de sua história, suas denominações variaram de Grupo Escolar Regente Feijó a Colégio Regente Feijó, de modo que num recorte de gerações ele é chamado, pelos mais velhos na cidade de "o grupo", passando para "o ginásio", até o mais comumente empregado, "colégio"; todos, de alguma forma, sugerindo alguma intimidade ou laço emocional àquele espaço. Mais que uma escola, mais que um ponto de referência geográfico, uma parte dos "lontrenses" e com os dois espaços referentes ao Colégio, no orkut, eu e muitos outros participantes daqueles espaços pudemos de alguma forma voltar ao Colégio - e daí o caráter mais especial dessas ligações: o religar. Nos religamos assim, aos professores, às brincadeiras de corredor, às "panelinhas" de amigos daquele espaço, especialmente vivenciados em nossas infâncias - parte de nossas vidas onde o Colégio foi parte substancial de nosso processo de socialização.

Em ambas as comunidades a esmagadora maioria dos tópicos e postagens são compostos por lembranças do passado: são esses pequenos reencontros de amigos e colegas e funcionários do Colégio com suas "lembranças boas e engraçadas", como os pequenos acidentes engraçados protagonizados por professores, as pequenas travessuras dos alunos e ex-alunos, ou mesmo, ao

10 A noção de religação aparece na obra de Maffesoli (2004a, 2004b, 2005a, 2005b, 2006) se referindo a uma movimento contemporâneo de "descentramento o indivíduo" como valor absoluto da modernidade em detrimento a laços compartilhados, à uniões afetivas - em alguns momentos, presenteístas - que privilegiam à forma das relações e não o conteúdo destas. Entretanto, no caso desta reflexão, optei, tão simplesmente, por positivar a idéia da possibilidade de se religar ao local - ao local geográfico, no caso, à cidade de Lontras. Isso sugere, à luz de Silva (2000), que fez uma análise da articulação de experiências on-line e off-line de usuários de canais de IRC geográficos, uma re-conexão das interações entre estas duas dimensões da vida social (on-line e off-line), novamente sugerindo que essas redes sócio-técnicas, apesar de amplas, continuam sendo locais em muitos pontos.

11 Além dessas comunidades, há também, atualmente as comunidades "automobilismo de Lontras" (160 membros), "Corrida do Paraíso - Lontras - SC" (110 membros), em referência às corridas de automobilismo que acontecem no autódromo Alceu Feldman, localizado no "Paraíso" - uma espécie de parque de lazer, com áreas para acampamento, piscinas, churrasqueiras e, mais recentemente o referido autódromo, localizado às margens da BR 470, no Paraíso, que com o passar dos anos começou a receber um número razoável de moradores aos seus arredores e hoje é considerado oficialmente um bairro do município de Lontras. Há também uma comunidade "O Sul é o Meu País (LONTRAS)" (25 membros), em referência a um movimento que se iniciou há algumas décadas no Rio Grande do Sul, buscando uma separação dos três Estados da região Sul do Brasil - Rio Grande do Sul, Paraná e Santa Catarina - dos demais Estados da Federação - este espaço se auto-descreve como "grupo de apoio" do município de Lontras. Há também uma comunidade que faz referência a comissão provisória de um partido político na cidade de Lontras, "PSB - Lontras - S.C", que conta atualmente apenas com o membro fundador do espaço. Como essas comunidades foram criadas mais recentemente, depois de minha saída de campo, elas não constituem esta etnografia. 


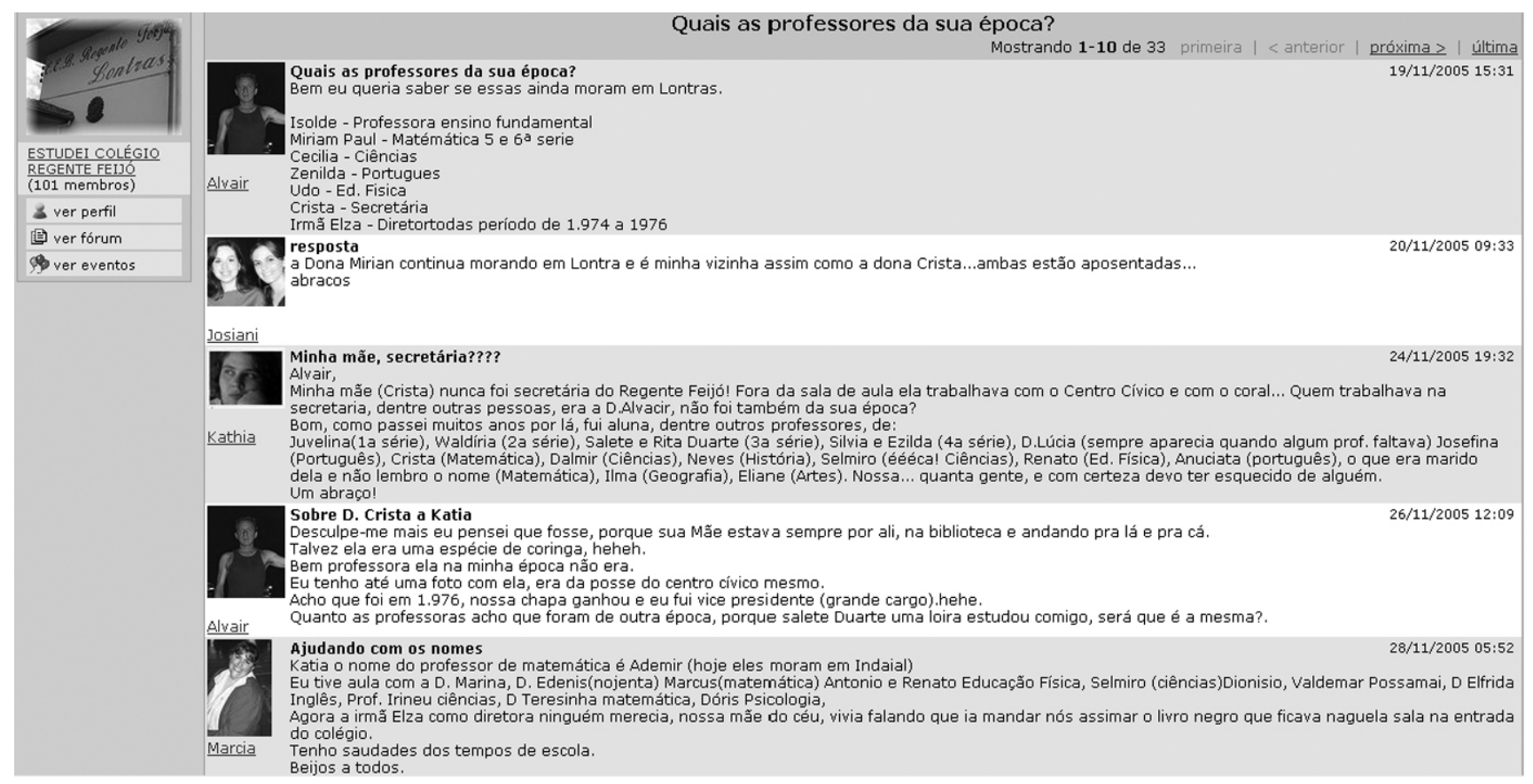

Figura 2: Quais os professores da sua época? www.orkut.com/CommMsgs.aspx-289790

falar das disciplinas, as matérias e assuntos que mais gostavam. Grosso modo, parece que, como escreve um participante da comunidade "E.E.B. Regente Feijó", "o tempo de escola é tão bom, a gente tem tantos amigos" e de alguma forma, se religar à escola, ou ao menos num espaço que fora constituído pelas pessoas que passaram pela escola, com o nome da escola, falando das experiências na escola, parece ter constituído um nó, nas redes do orkut, onde se pode viver, mesmo que de outras maneiras, a coletividade e o sentimento de tantos amigos, próprios do Colégio de Lontras: num constante transitar entre as lembranças do passado de um e outro e mesmo da escola, se pôde ligar-se e religar-se a um e outro, novamente naquele espaço, agora, no orkut.

$\mathrm{Na}$ Antropologia "brasileira", os estudos dedicados à "memória coletiva", possuem campos teóricometodológicos bem consolidados e, não era sob esta ótica que eu desejava trabalhar em minha pesquisa, mas o campo exigiu que eu fizesse uma revisão, mesmo que muito pouco aprofundada, das bibliografias destes estudos, tendo em vista que não pude deixar de considerar que as memórias da cidade de Lontras emergiam naquela localidade das interações no orkut. Geralmente evocadas individualmente - um ou outro participante, evocando algum episódio isolado relacionado à cidade e, especialmente ao Colégio - aos poucos lembranças iam se tornando o cimento constituidor de muitas das relações que se engendravam naquele espaço. Dessa forma, como classicamente sugere Halbwachs (2004), essas memórias individuais não foram compreendidas como isoladas ou fechadas; os participantes, de uma ou outra forma se reportavam a "pontos de referência que existem fora deles e que são fixados pela sociedade" (Halbwachs, 2004, p. 58) de tal forma a constituir uma espécie de mosaico de pequenas experiências pessoais, subjetivas, relacionadas a umas ou outras realidades objetivas comuns, que aos poucos constituía e reconstituía toda uma história daquele espaço e de alguns períodos de tempo, como parte das construções presentes de memória coletiva.

Em um tópico intitulado, "Quais os professores de sua época?", da comunidade "Estudei Colégio Regente Feijó", um dos participantes do espaço que foi aluno no Colégio nos anos de 1970, apresentou os professores que compunham o corpo docente de sua época. No tópico, ele queria saber se "essas [pessoas] ainda moram em Lontras". Entretanto, ele deu início a uma espécie de negociação da história do Colégio naquele período, na rememoração daqueles que naquela época também estudaram lá; começávamos a construir uma espécie de memória do Colégio e conseqüentemente, da cidade de Lontras.

Nesse trecho de conversa, aos poucos a lista inicial de nomes de professores que Alvair postou na comunidade, foi ganhando complementações, como a correção de algumas informações, inclusão de outros nomes e os recortes de geração, já que os participantes que começaram a postar no tópico apresentaram, como Alvair pede no título do tópico, os professores de sua época, o que aos poucos transformou a pequena lista de professores iniciada Alvair, numa grande lista que atravessou décadas do Colégio, até eu, que anteriormente contribuíra com a lista de nomes de meus professores, fui listado por outro participante da comunidade como o seu professor. Enfim, as memórias começaram a ser construídas numa negociação do passado, como no caso de Kathia que traz correções à 
informação de Alvair sobre Dona Crista ser secretária do Colégio, ao passo que mais abaixo Marcia ajuda Kathia em um nome de professor que ela não lembra - Ademir, de matemática - já situando onde ele e sua esposa, também professora, atualmente residem, o que ajuda a responder a pergunta inicial de Alvair, sobre quem ainda mora em Lontras. Como Alvair é alguém que morou em Lontras por alguns anos, mas que há muito tempo esta fora da cidade, este foi um espaço onde ele soube, mais do que as informações que ele pede na pergunta do tópico, de outros acontecimentos da cidade, ligados a sua pergunta inicial, como quem está morando ou não na cidade, ou ainda, algumas travessuras, ou outras experiências que um ou outro participante resolvia contar, em relação àqueles professores ou disciplinas. Ao longo do tópico, essas pequenas informações para além da pergunta inicial, foram compondo histórias paralelas, que na verdade compuseram uma grande história do Colégio e mesmo da cidade de Lontras.

Assim, ao mesmo tempo que essas informações para além da questão central do tópico iam acontecendo, eram criados outros tópicos a fim de recordar pequenas histórias, algumas experienciadas juntas, outras em torno de algum ponto comum - histórias de sala de aula, histórias com a diretora, histórias de datas especiais - que dialogicamente, eram passadas e reconstruídas em espécie de filtro (Bertaux, 1997) entre os participantes, a fim de aos poucos serem abandonados os aspectos mais subjetivos dessas experiências, construindo experiências que pudessem caracterizar uma espécie de memória coletiva daqueles espaços-tempo aos quais se referiam as postagens; considerando-se que, como sugere Alfred Schütz, citado por Daniel Berteaux (1997) "toute expérience de vie comporte une dimension sociale" (Schütz, apud Bertaux, 1997, p. 45). Assim, o conteúdo daqueles tópicos, mesmo que altamente carregados por dimensões subjetivas, estavam de alguma forma reconstruindo não apenas histórias pessoais em pequenas narrativas de vida, mas histórias de um espaço que foi experienciado por estes sujeitos em outros tempos e que constituem assim as suas experiências não apenas pessoais, mas sociais, sem deixar de considerar que "a lembrança é uma imagem construída pelos materiais que estão, agora, à nossa disposição, no conjunto de representações que povoam nossa consciência atual" (Bosi, 2004, p. 55). Outrossim, considerando que estas experiências narradas estavam altamente ligadas aos contextos e interlocutores dos participantes daquele espaço, elas não compuseram a história do Colégio em sua totalidade: a experiência vivida por um, ou outro participante nos tempos de Colégio já havia sido ressignificada pelas percepções que estes foram construindo ao longo das suas vidas acerca daquelas experiências. Além disso, como eu também era participante destas memórias, fomos compondo um texto que incorporava nossas vozes umas às outras no ambiente. Nesse sentido, aquilo que cada um poderia compreender por outro "já não [era] o outro, mas a descrição cultural em si” (Clifford, 1987 apud Geertz, 2002, p. 175) condensado em si, resultando em um tipo de escrita construída com base em uma "subjetividade dialógica" (Versiani, 2002, p. 05) que, enfatizava a presença desse outro na escrita de si, acabando por incluir esses outros - vozes, selves - em nossos discursos (em nossos textos), mediante as memórias e as condições sociohistóricas daqueles processos de construção de subjetividades (Guattari e Rolnik, 2005; González Rey, 2003; 2007).

De qualquer forma, para além da construção das muitas pequenas histórias paralelas, o que pareceu fundamental naquele tópico - um dos primeiros criados naquele espaço - foi o movimento de fazer com que vários antigos amigos e colegas de turma pudessem se reencontrar, ou mesmo saber de pessoas que não estavam no orkut, e aos poucos seguiram-se várias postagens que se remetiam diretamente a um ou outro participante que anteriormente postara a resposta ao tópico e que eram reconhecidos por outros participantes da comunidade que os abordavam com "é você mesmo?", "quanto tempo", "ainda lembra de mim, estudamos juntos", "por onde anda o nosso colega...". Começa um aparente movimento de religar antigas amizades, antigas relações.

O tópico "nostalgia... pra você Alvair", foi um exemplo emblemático nesse mesmo espaço. Criado por José Carlos em dezembro de 2005, o tópico ultrapassou quinhentas postagens, sendo quase cem por cento delas trocadas entre José Carlos e Alvair, amigo de escola de José Carlos. No tópico, José Carlos deixa claro o caráter nostálgico das postagens - como ele nomeia o tópico - ao falar dos antigos amores, "do José Carlos, menino lindo de olhos verdes que amou a Fábia também menina linda de olhos negros como a noite". Lembranças que são registradas no orkut "e que fiquem registradas enquanto o orkut durar". Um pouco mais acima um outro participante fala do presente de Fábia, "daquele amor que nunca passou de um beijinho no rosto", sobre o qual José Carlos escreve mais adiante se sentir mais próximo, pelo simples fato "de estar novamente no colégio", conversando com gente do Colégio, com seus amigos e colegas, "mesmo que no orkut", mesmo que como ele ainda acrescenta, "o passado deve ficar onde está mesmo". Ele não era um passado que estava sendo vivido, era um presente que reaproximava o passado - "é do presente que parte o chamado ao qual a lembrança responde" (Bergson apud Bosi, 2004, p. 48 - grifo meu) e essa lembrança compôs um presente que era uma experiência vivida e sentida de maneira diversa do passado naquele ambiente.

De todo modo, o ponto central dessa breve reflexão reside na percepção de que, às idas e vindas nas redes sociotécnicas, para além da potencialidade 
de desterritorialização oferecida pelo ciberespaço, haveria um intenso movimento de retorno à terra, ao local. Isso aconteceria pelo fato de que essas redes relativizam o local e o global, já que "por mais globalizantes e universalizantes que pareçam, trata-se de fenômenos locais" (Rifiotis, 2006, s/p). Associada a esta idéia, fica também a sugestão de Maffesoli (2004b; 2006) de que o local faz laços. Havia um laço que me prendia à cidade de Lontras e da mesma forma, um laço que prendia tantos outros participantes das comunidades que constituíram, nelas, no MSN e na própria cidade de Lontras, um ambiente de interação. Ao mesmo tempo que nos fomos enredando naquele ambiente, nos prendíamos cada vez mais ao local, reencontrando espaços de constituição e velhas amizades e as pequenas histórias, discussões, discordâncias e concordâncias que com a intervenção e contribuição dos participantes do espaço, aos poucos foi se fazendo com que todos, como nas palavras de um participante, "se sentissem em casa de novo - graças ao orkut". Graças aquele local tão global que permitiu tantos reencontros; graças aquele global, tão local.

\section{Referências}

BAUMAN, Zygmunt. Comunidade: a busca por segurança no mundo atual. Rio de Janeiro: Jorge Zahar Editor, 2003.

BERTAUX, Daniel. Les récits de vie: perspective ethnosociologique. Paris: Nathan, 1997.

BOSI, Ecléa. Memória e Sociedade: lembranças dos velhos. Rio de Janeiro: Companhia das Letras, 2004.

CASTELLS, Manuel. A Galáxia da Internet: reflexões sobre a internet, os negócios e a sociedade. Rio de Janeiro: Jorge Zahar Editor, 2003

CLIFFORD, James. A Experiência Etnográfica: antropologia e literatura no século XX. Rio de Janeiro: UFRJ, 2002.

DE CERTEAU, Michel. A Invenção do Cotidiano: 1. Artes de Fazer. 9. ed. Petrópolis: Vozes, 2003.

GEERTZ, Clifford. Obras e Vidas: o antropólogo como autor. Rio de Janeiro: UFRJ, 2002.

GUIMARÃES, JR. Mário J. L. Vivendo no Palace: etnografia de um ambiente de sociabilidade no ciberespaço. Dissertação (Mestrado). Florianópolis: PPGAS/UFSC, 2000.

" "De Pés Descalços no Ciberespaço: tecnologia e cultura no cotidiano de um grupo social on-line". In: Horizontes Antropológicos. ano 10, n. 21. Porto Alegre: UFRGS, 2004, p. 123-154.

GONZÁLEZ REY, Fernando. Sujeito e Subjetividade: uma aproximação histórico-cultural. São Paulo: Thomson Learning, 2003.

Psicoterapia, Subjetividade e Pós-Modernidade: uma aproximação histórico-cultural. São Paulo: Thomson Learning, 2007.

GUATTARI, Félix; ROLNIK, Suely. Micropolítica: cartografias do desejo. 7. ed. Petrópolis: Vozes, 2005.

HALBWACHS, Maurice. A Memória Coletiva. São Paulo: Centauro, 2004.

HALL, Edward. "A System for the Notation of Proxemic Behavior”. In: American Anthropologist. v. 65, 1963, p. 1003-1026.

A Dimensão Oculta. Rio de Janeiro: Francisco Alves, 1989.

HANNERZ, Ulf. "Fluxos, Fronteiras, Híbridos: palavras-chave da antropologia transncional". Mana v.3, n1., 1997, p.739.

LATOUR, Bruno. Jamais Fomos Modernos: ensaio de antropologia simétrica. São Paulo: Editora 34, 2005.
MAFFESOLI, Michel. Sobre o Nomadismo: vagabundagens pós-modernas. Porto Alegre: Sulina, 2001.

Notas Sobre a Pós-Modernidade: o lugar faz o elo.

Rio de Janeiro: Atlântica Editora, 2004a.

Le rythme de la vie: variations sur les sensibilités postmodernes. Paris: La Table Ronde, 2004b. . "A Ética da Estética". In: . O Mistério da Conjunção: ensaios sobre comunicação, corpo e socialidade. Porto Alegre: Sulina, 2005a, p. 11-28. "O Lúdico e a Socialidade". In: O Mistério da Conjunção: ensaios sobre comunicação, corpo e socialidade. Porto Alegre: Sulina, 2005b, p. 47-60.

O Tempo das Tribos: o declínio do individualismo nas sociedades de massa. 4. ed. Rio de Janeiro: Forense Universitária, 2006.

RIFIOTIS, Theophilos. "Antropologia do Ciberespaço: questões teórico-metodológicas sobre pesquisa de campo e modelos de sociabilidade". Antropologia em Primeira Mão, n. 51. Florianópolis: PPGAS/UFSC, 2002.

"Duas ou Três Coisas Sobre Elas, as Comunidades Virtuais". XXVII Encontro Anual da Anpocs. Caxambu, 2003 (Impresso).

SILVA, Ana Maria Carneiro da. Reconectando a Sociabilidade On-Line e Off-Line: trajetórias, poder e formação de grupos em canais geográficos no Internet Relay Chat. Dissertação (Mestrado). Campinas: Departamento de Sociologia/UNICAMP, 2000.

SIMMEL, Georg. "O Estrangeiro". In: FILHO, Evaristo de Morais. Georg Simmel. Coleção Sociologia. São Paulo: Editora Ática, 1983a, pp. 182-188.

"Conflito e Estrutura do Grupo". In: FILHO,

Evaristo de Morais. Georg Simmel. Coleção Sociologia. São Paulo: Editora Ática, 1983b, pp. 150-164. "La Aventura". In: ______. Cultura Femenina y Otros Ensayos. Barcelona: Alba Editorial, 1999, pp. 1534.

"O Nível Social e o Nível Individual". In: Questões Fundamentais da Sociologia: indivíduo e sociedade. Rio de Janeiro: Jorge Zahar Editor, 2006, pp. 39-58.

VERSIANI, Daniela. Texto Coletivo e Auto-Etnografia: alternativas conceituais às biografias e autobiografias. Rio de Janeiro: Departamento de Letras da PUC-Rio, 2002, pp. 01-06. 


\title{
Outras Referências
}

ARTONI, Camila. A vida na era do Orkut - Reportagem de Capa. Revista Galileu, n. 158, setembro de 2004. Disponível em: http://revistagalileu.globo.com/ Galileu/0,6993,ECT803827-1706,00.html. Acesso em: 17/10/2004.

MARTHE, Marcelo. É como o Orkut... mas Tem Trilha Sonora. VEJA (Revista). 12 de abril de 2006, pp. 65-68.

NOGUEIRA, Tânia et al. Você também está no Orkut - Reportagem de Capa. ÉPOCA (Revista), 326, 16/08/2004. Disponível em: http://revistaepoca.glo-
bo.com/Revista/Epoca/0,,EDG65928-5990-326,00FESTA+BRASILEIRA+NA+REDE.html. Acesso em: 19/10/2004.

RIFIOTIS, Theophilos. Redes Globais dão Origem a Guetos Locais. (Entrevista). Jornal Folha de São Paulo OnLine, 29 de novembro de 2006. Disponível em: http:// www1.folha.uol.com.br/fsp/informat/fr2911200613. htm. Acesso em: 04/12/2006.

SUPERINTERESSANTE (Revista). Orkut: como entender este fenômeno. Setembro de 2004, pp. 32-37.

\section{Global networks, local ties: memory of the city of Lontras in Orkut}

\begin{abstract}
As part of some reflections arising from my research for my MA in anthropology, where I did an ethnography about the environment built in the tangling of some communities in orkut, MSN and the city of Lontras, in the State of Santa Catarina, in this article I reflect especially about one of several forms and qualities of interaction in socio-technical networks: the possibility of construction of collective memory. The central node of this discussion takes place in an orkut community that "honors the college" of the city of Lontras that enabled the [re] meeting of students from different generations who built an environment of interaction where people can understand the character of the town and globality that involves all these networks.
\end{abstract}

Key-words: anthropology of cyberspace; socio-technical networks; collective memory; locality; globality.

Data de recebimento do artigo: 15 de fevereiro de 2008

Data de aprovação do artigo: 22 de abril de 2008 